\title{
Guillaume-Thomas Raynal, Histoire philosophique et politique des établissements et du commerce des Européens dans les deux Indes
}

\section{Peter Balazs}

\section{(2) OpenEdition Journals}

Édition électronique

URL : http://journals.openedition.org/studifrancesi/5639

DOI : 10.4000/studifrancesi.5639

ISSN : 2427-5856

Éditeur

Rosenberg \& Sellier

\section{Édition imprimée}

Date de publication : 1 septembre 2011

Pagination : 412-413

ISSN : 0039-2944

\section{Référence électronique}

Peter Balazs, « Guillaume-Thomas Raynal, Histoire philosophique et politique des établissements et du commerce des Européens dans les deux Indes ", Studi Francesi [En ligne], 164 (LV | II) | 2011, mis en ligne le 30 novembre 2015, consulté le 09 janvier 2021. URL : http://journals.openedition.org/studifrancesi/ 5639 ; DOI : https://doi.org/10.4000/studifrancesi.5639

Ce document a été généré automatiquement le 9 janvier 2021.

\section{cc) $(9)$}

Studi Francesi è distribuita con Licenza Creative Commons Attribuzione - Non commerciale - Non opere derivate 4.0 Internazionale. 


\section{Guillaume-Thomas Raynal, Histoire philosophique et politique des établissements et du commerce des Européens dans les deux Indes}

Peter Balazs

\section{RÉFÉRENCE}

GUILLAUME-THOMAS RAYNAL, Histoire philosophique et politique des établissements et $d u$ commerce des Européens dans les deux Indes, Tome I, livres I-V, Édition critique établie par le comité éditorial: Anthony STRUGNeLl (directeur), Andrew BROWN, Cecil Patrick COURTNEY, Georges DULAC, Gianluigi GOGGI et Hans-Jürgen LÜSEBRINK, Ferney-Voltaire, Centre International d'Étude du XVIII ${ }^{e}$ siècle, 2010, 769 pp.

1 Dans son introduction générale. H-J. LÜSEBRINK évoque rapidement la fortune - sa popularité à la fin $d u x_{\text {XIII }}^{e}$ siècle, son oubli tout au long du $\mathrm{XIX}^{\mathrm{e}}$ siècle, et sa redécouverte dans la seconde moitié du $\mathrm{xx}^{\mathrm{e}}$ - de ce texte exceptionnel, dont l'édition de 1780 (la dernière version préparée sous la direction de Raynal) est retenue pour la réédition, dont ce volume richement documenté n'est que le début. Lüsebrink traite également de la question des collaborateurs et de la réception de l'Histoire des DeuxIndes. On y trouve aussi une bibliographie sommaire des éditions de l'ouvrage, ainsi qu'une liste détaillée des cartes et des tableaux statistiques. Chaque livre est précédé d'une présentation qui renseigne les lecteurs sur la structure, les sources, l'évolution et l'importance du livre en question.

2 Le premier livre, intitulé Découvertes, guerres et conquêtes des Portugais dans les Indes Orientales est établi et présenté par Peter Jімаск. Il s'agit d'un résumé de l'histoire d'Europe jusqu'aux grandes découvertes et d'une sorte d'introduction à l'ouvrage entier, puisque Raynal continue par la présentation des voyages d'exploration et des 
conquêtes de la première puissance coloniale, c'est-à-dire le Portugal. Le second livre, Établissemens, guerres, politique et commerce des Hollandais dans le Indes Orientales, est présenté par Guido ABBATISTA. Le sujet central en est l'économie et la politique hollandaises, une réflexion sur l'histoire de la VOC (Vereenigde Oostindische Compagnie) et, indirectement, une méditation philosophique sur la république des Provinces-Unies et sur le caractère et les institutions d'un État républicain en général. Le fil conducteur du livre en question est le constat que l'entreprise coloniale exerce une influence très peu salutaire sur les vertus civiques et le patriotisme.

3 La présentation du troisième livre, intitulé Établissements, commerce et conquêtes des Anglois dans les Indes Orientales est l'œuvre d'Anthony STRUGNELL, qui souligne que des quatre premiers livres relatant les succès et les échecs des grandes nations commerçantes, seul le livre consacré aux Anglais est l'histoire d'un succès. La narration de la marche triomphale de l'East India Company doit néanmoins être interprétée dans le contexte historique de la fin du xviII ${ }^{\mathrm{e}}$ siècle et on ne doit pas oublier non plus que Raynal condamne les activités anglaises au Bengale comme la plus atroce des oppressions. Le quatrième livre, Voyages, établissements, guerre et commerce des François dans les Indes Orientales, établi par Florence D'souzA, est non seulement la narration d'un échec, mais aussi une leçon à tous les Européens installés en Inde, afin qu'ils adoptent envers les indigènes un nouveau comportement, qui sera marqué par l'amitié, la douceur et la modération. Le livre en question formule aussi de vives critiques à l'égard de l'intervention gouvernementale dans la gestion de la Compagnie des Indes. Le cinquième (et dernier) livre que renferme ce volume, le Commerce du Danemarck, d'Ostende, de la Suede, de la Prusse, de l'Espagne, de la Russie, aux Indes Orientales. Questions importantes sur les liaisons de l'Europe avec les Indes est établi et présenté par Muriel вRоT. Dans ce livre, Raynal étudie ensemble l'intervention tardive et la participation en fin de compte assez modeste de ces nations ayant créé leurs propres compagnies orientales.

4 La présentation et le texte des cinq livres sont suivis d'une table alphabétique des matières et des variantes qu'on peut trouver dans les diverses éditions (1770, 1774, 1782) de l'ouvrage. Le volume se clôt sur une liste détaillée des contributions de Diderot aux livres I-V: Gianluigi GOGGI y a pris soin de distinguer entre les passages (figurant dans le fonds Vandeul) qui sont certainement attribuables à Diderot et ceux dont l'attribution n'est que très vraisemblable. Au total, c'est un travail philologique exemplaire dont on attend la suite avec impatience! 